\section{Complication after endoscopic ultrasound-guided fine-needle aspiration (EUS-FNA) of rectal lesion}

A 50-year-old woman was referred to undergo an endoscopic ultrasound-guided fine-needle aspiration (EUS-FNA) of a lesion in the posterior region of the rectum. Informed consent was obtained. EUS, performed with a linear probe (3830UT, Pentax, Hamburg), confirmed a hypoechoic lesion with well-defined margins at $10 \mathrm{~cm}$ from the anal sphincter, between the posterior region of the rectum and sacrum $(33 \mathrm{~mm})$. Prophylactic antibiotics were administered (ampicillin $2 \mathrm{~g}$; gentamicin $80 \mathrm{mg}$ intravenously [IV]). Conscious sedation was initiated with midazolam, $2 \mathrm{mg}$ IV. EUS-FNA used a $25 \mathrm{G}$ ultrasound needle (Wilson-Cook Medical Inc., USA) ( $\bullet$ Figure 1). No complications were encountered. Cytological examination of the lesion revealed amorphous granular material, numerous squamous cells without atypical features, rare stromal cells, and few normal glandular aggregates; no malignant cells were found ( $\bullet$ Figure 2). Five days following the procedure, the patient complained of pain in the posterior region of the rectum, and experienced fever and spontaneous cutaneous drainage. EUS showed the lesion to be hypoechoic, with anechoic areas and undefined margins, compatible with pelvic abscess or hematic extravasation after EUS-FNA. The patient was hospitalized and underwent clinical revalutation. Magnetic resonance imaging revealed features in the presacral-coccyx region consistent with an abscess surrounded by granular tissue. The patient was discharged in good clinical condition 10 days later.

EUS-FNA has been shown to be a feasible and safe technique to obtain cytological specimens of submucosal, extrinsic gastrointestinal, pancreatic lesion masses, or pathologic lymph nodes, as well as cystic structures [1 - 3]; the risk of bacteremia is low [4-5]. In this clinical case, we used EUS-FNA to better characterize the lesion; the reported lesion did not show cyst features and therefore the risk asso-

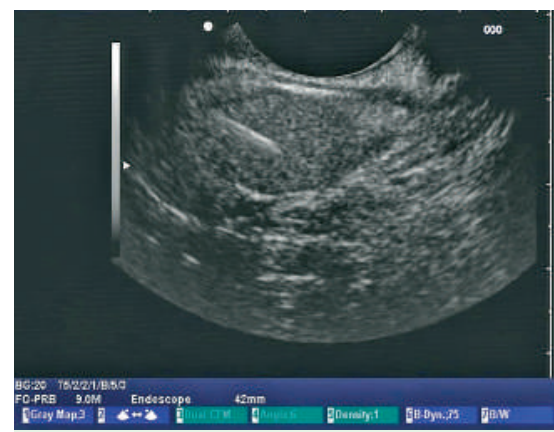

Figure 1 Endoscopic ultrasound-guided fineneedle aspiration of a rectal lesion.

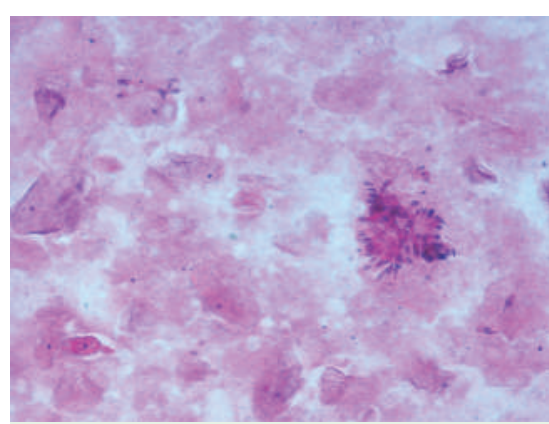

Figure 2 Cytological examination: EE $200 \times$

ciated with EUS-FNA, as for solid lesions, was negligible. In this case, as in all our cases of transrectal biopsies, prophylaxis with antibiotics was administered. The complication observed after EUS-FNA could be limited by administering antibiotics in the days following the procedure, even though there are no published data on the usefulness of pharmacologic prophylaxis [4].

Endoscopy_UCTN_Code_CPL_1AL_2AZ

Endoscopy_UCTN_Code_CPL_1AL_2AF

\section{G. Mezzi ${ }^{1}$, P. G. Arcidiacono ${ }^{1}$, S. Carrara ${ }^{1}$, M. Freschi ${ }^{2}$, C. Boemo ${ }^{1}$, P. A. Testoni ${ }^{1}$ \\ 1 Department of Gastroenterology and Gastrointestinal Endoscopy, IRCCS Vita- Salute University, San Raffaele Scientific Institute, Milan, Italy \\ 2 Department of Histopathology, IRCCS Vita-Salute University, San Raffaele Sci- entific Institute, Milan, Italy}

\section{References}

1 Fusaroli P, Caletti G. Endoscopic ultrasonography: current clinical role. Eur J Gastroenterol Hepatol 2005; 17: $293-301$

2 Sasaki Y, Niwa Y, Hirooka Y et al. The use of endoscopic ultrasound-guided fine-needleaspiration for investigation of submucosal and extrinsic masses of the colon and rectum. Endoscopy 2005; 37: 154- 160

3 Chen VK, Eloubeidi MA. Endoscopic ultrasound-guided fine-needle aspiration of intramural and extraintestinal mass lesions: diagnostic accuracy, complication assessment and impact on management. Endoscopy 2005; 37: 984- 989

4 ASGE guideline: complications of EUS. Gastrointes Endosc 2005; 61: 8-12

5 Hirota WK, Petersen K, Baron TH et al. Guidelines for antibiotic prophylaxis for GI endoscopy. Gastrointest Endosc 2003; 58: 475-482

Bibliography

DOI 10.1055/s-2007-966318

Endoscopy 2007; 39: 137

(c) Georg Thieme Verlag KG Stuttgart · New York . ISSN 0013-726X

Corresponding author

\section{G. Mezzi, MD}

Department of Gastroenterology and

Gastrointestinal Endoscopy

IRCCS Vita-Salute University

San Raffaele Scientific Institute

Via Olgettina, 60

20132 Milan

Italy

Fax: +39-02-26432504

mezzi.gianni@hsr.it 